\title{
Olimpíada Brasileira de Física das escolas públicas: uma análise dos conteúdos e da evolução do exame em todas suas edições ${ }^{+*}$
}

João Paulo Casaro Erthal ${ }^{1}$

Departamento de Química e Física

Universidade Federal do Espírito Santo

Matheus de Oliveira Louzada

Licenciando em Física

Universidade Federal do Espírito Santo

Alegre - ES

\section{Resumo}

Em nosso país, projetos estão surgindo com o objetivo de estimular e despertar o interesse dos estudantes por distintas áreas do conhecimento e, alguns deles, têm tomado grandes proporções, atingindo a esfera nacional. Um bom exemplo desses projetos são as olimpíadas escolares. Neste artigo iremos discorrer sobre a Olimpíada Brasileira de Física das Escolas Públicas (OBFEP) e apresentar uma análise e caracterização das questões dessas provas, evidenciando os conteúdos mais abordados em todas as edições do exame. Os resultados mostram que, em todos os níveis, o conteúdo mais evidenciado nas questões da OBFEP foi mecânica e que em suas resoluções, a utilização de cálculos matemáticos era mais necessária do que o conhecimento de conceitos físicos. Além disso, percebermos a evolução no perfil das provas, que em sua primeira edição estava menos contextualizada e estruturada ao redor de um tema quando comparada aos anos posteriores.

Palavras-chave: Olimpíada Brasileira de Física das Escolas Públicas; Análise de questões; Perfil das provas.

\footnotetext{
${ }^{+}$Brazilian Olympiad of Physics to public schools: an analysis of the content and evolution of the exam in all its editions

* Recebido: maio de 2016.

Aceito: setembro de 2016.

${ }^{1}$ E-mail: jperthal@gmail.com

2 E-mail: matheusoli.louzada@hotmail.com
} 


\begin{abstract}
In our country, projects are emerging in order to stimulate and arouse the interest of students in different areas of knowledge, and some of them have taken great proportions, reaching a national level. A good example of these projects is the school olympiads. In this article we will discuss about the Brazilian Physics Olympiad to Public Schools (OBFEP), and present an analysis and characterization of the issues showing the most discussed content in all editions of the exam. The results show that, in all levels, the most discussed content was mechanics, and, in its resolutions, the use of mathematical calculations was more necessary than the knowledge of physical concepts. Also, we realized the developments in the exam's profile, which in its first edition was less contextualized and structured around a theme when compared to later years.
\end{abstract}

Keywords: The Brazilian Physics Olympiad to Public Schools; Analysis of questions; Profile of the tests.

\title{
I. Introdução
}

No decorrer dos anos, o ensino de ciências tem atravessado inúmeros conflitos, visto que cada vez se torna mais complicado ensinar e envolver os estudantes em atividades escolares. Na busca por soluções que tornem os estudantes mais participativos e que despertem o interesse desses por ciências, foram iniciados diferentes programas, dentre eles as olimpíadas escolares. No Brasil, anualmente, organizam-se Olimpíadas de Matemática e Língua Portuguesa, para as escolas públicas, patrocinadas pelo Governo Federal desde 2006. Outras, como a Olimpíada Brasileira de Física (OBF) vêm sendo organizada pela Sociedade Brasileira de Física (SBF), para todos os estudantes do Ensino Médio e estudantes das últimas séries, oitavo e nono anos, do Ensino Fundamental, com apoio de órgãos de fomento como o Conselho Nacional de Desenvolvimento Científico e Tecnológico (CNPq) (REZENDE; OSTERMANN, 2012).

Numa esfera global, as Olimpíadas de Física se iniciaram em 1960, quando um pequeno grupo de três professores de Física da Europa decidiu organizar tal competição. Em 1962, foi realizada a primeira Olimpíada Internacional de Física (OIF), que ocorreu em Varsóvia na Polônia (VIANNA et al., 2000).

No Brasil, tal proposta começou a ser discutida na década de 1980 e em 1985 ocorreu a primeira competição dessa natureza, voltada para a área de Física, no estado de São Paulo. Nos anos seguintes, propostas similares surgiram de forma independente em outros estados brasileiros, até que em 1998 a SBF toma a frente do projeto e, em 1999, é realizada a primeira Olimpíada Brasileira de Física. 
Após a criação da OBF e considerando seu sucesso, ficou evidente que este era um bom caminho a ser percorrido na busca para encantar e estimular os estudantes a se aprofundarem nos conteúdos de Física. No entanto, a prova da OBF possui um nível de dificuldade elevado e com isso muitos estudantes de escolas públicas se sentiam desestimulados a participar. Para solucionar esta dificuldade criou-se um projeto semelhante voltado para a rede pública de ensino.

Assim nasceu a Olimpíada Brasileira de Física das Escolas Públicas (OBFEP) em 2010, com caráter de Projeto Piloto, aplicado nos estados da Bahia, Goiás, Piauí e São Paulo. Em 2011, ainda como piloto, a OBFEP aconteceu nos quatro estados citados, e mais Maranhão e Mato Grosso. A partir de 2012 a Olimpíada Brasileira de Física das Escolas Públicas é um programa permanente da Sociedade Brasileira de Física (SBF), aplicado em todo Brasil (NAKAMURA; MARTINS; GUTMANN, 2012).

Atualmente, a OBFEP é realizada em duas fases. A primeira fase ocorre na escola do estudante participante, geralmente no mês de agosto. A segunda fase é realizada, em outubro, em locais determinados pelo Coordenador Estadual, e dela participam os estudantes que atingiram o número mínimo de acertos na primeira fase, sendo este definido pela comissão da OBFEP após análise do desempenho dos estudantes nessa etapa. As questões da primeira fase da prova são teóricas e objetivas e as da segunda fase são discursivas, com uma parte teórica e uma parte prática.

A OBFEP tem como objetivo despertar e estimular o interesse pela Física e pelas ciências, proporcionando desafios aos estudantes e abrindo caminhos para identificar estudantes talentosos, incentivando-os a ingressar nas áreas científicas e tecnológicas, aproximando assim, as universidades, institutos de pesquisa e sociedades científicas das escolas públicas. Além disso, incentiva o aperfeiçoamento dos professores das escolas públicas contribuindo para sua valorização profissional e para a melhoria da qualidade da Educação Básica, promovendo a inclusão social por meio da difusão do conhecimento (OBFEP, 2016).

A cada ano o programa atinge um número maior de escolas públicas participantes. No ano de 2015, 2.311 escolas realizaram cadastro para participação dos seus estudantes na OBFEP. O maior número de escolas credenciadas nesse ano se deu no estado de São Paulo, com 356 inscrições, seguido por Ceará, com 320 inscrições, e Rio de Janeiro com 183 escolas inscritas. Os estados com menor quantitativo de escolas inscritas foram Acre, com 11 inscrições, e Amapá, com apenas 07 escolas credenciadas (OBFEP, 2015).

Esses dados evidenciam um grande quantitativo de estudantes participantes. O conhecimento de características das provas da OBFEP pode servir como material de auxílio ao professor para o ensino e avaliação da aprendizagem, bem como para o aprofundamento dos estudantes interessados.

Em vista disso, este trabalho objetiva investigar os conteúdos das questões que constituem as provas da OBFEP e a forma como são abordados, de modo a se poder traçar um perfil dessas avaliações ao longo dos anos. 


\section{Desenvolvimento}

A ideia inicial deste trabalho se deu após a aplicação da OBFEP do ano de 2014, visto que algumas de suas questões foram canceladas por apresentarem inconsistências. Este fato trouxe à tona questionamentos sobre como se dá todo o procedimento desta olimpíada, desde sua estrutura e financiamento até a aplicação dos exames. Inicialmente, foi realizada uma busca por todas as provas da OBFEP e, na sequência, foi realizado um estudo detalhado, classificando as questões dessas provas em diversos aspectos. As provas analisadas compreendem todo o período em que o exame foi aplicado, desde seu início, em 2010, até o último exame, que ocorreu em 2015. A análise dos conteúdos de cada questão foi baseada na divisão de conteúdos feita por Alberto Gaspar em seu livro "Física" (GASPAR, 2005).

Nas duas primeiras edições o exame ocorreu em caráter de projeto piloto, logo, nestes seis anos de execução da OBFEP, existem duas estruturas distintas de provas. Nos anos de 2010 e 2011 a OBFEP teve uma única etapa com 15 questões objetivas e 05 discursivas (NAKAMURA; MARTINS; GUTMANN, 2012). Já nos anos de 2012 a 2015 a OBFEP teve duas etapas: a primeira teórica e objetiva, composta por 15 questões; e a segunda discursiva, com uma parte teórica e uma parte prática, composta por 05 questões discursivas e 01 questão prática. Em todas as suas edições, o exame foi divido em três níveis, apresentados na Tabela 1.

Tabela 1: Nível dos estudantes de acordo com a escolaridade.

\begin{tabular}{|l|l|}
\hline Nível A & Estudantes matriculados no $9^{\mathrm{o}}$ ano do Ensino Fundamental \\
\hline Nível B & Estudantes matriculados nas $1^{\mathrm{a}}$ e $2^{\mathrm{a}}$ séries do Ensino Médio \\
\hline Nível C & Estudantes matriculados nas $3^{\mathrm{a}}$ série e $4^{\mathrm{a}}$ série (onde houver) do Ensino Médio \\
\hline
\end{tabular}

Vale ressaltar que o nível B, nos anos de 2010 e 2011, apresentou 20 questões objetivas e 08 dissertativas, sendo que algumas estavam assinaladas como exclusivas para estudantes do $1^{\circ}$ ano, que poderiam escolher livremente 15 questões objetivas, e 05 dissertativas. Já os estudantes do $2^{\circ}$ ano deveriam tentar solucionar todas as questões da prova, exceto às exclusivas para o $1^{\circ}$ ano. Nos demais anos as provas para o nível B aconteceram quase da mesma maneira, com a diferença dessas possuírem apenas questões objetivas na primeira etapa. Esta opção de escolhas, segundo o regulamento da OBFEP, é necessária em função das diferenças de grades curriculares nas diversas unidades da federação.

A existência de estruturas distintas nos levaram a realizar a análise dos exames dividindo-os em duas partes. A primeira parte se refere aos exames dos anos de 2010 e 2011 e a segunda parte aos anos de 2012, 2013, 2014 e 2015. 


\section{Primeira parte: análise das provas dos anos de 2010 e 2011}

No ano de 2010, aconteceu a $19^{\text {a }}$ Copa do Mundo de Futebol, um dos eventos mais importantes e populares no mundo dos esportes. A OBFEP definiu o tema do exame como "Ano da Copa do Mundo de Futebol na África do Sul”, e a maior parte do exame foi elaborada seguindo a temática do futebol. A prova apresentava um texto introdutório que deveria ser utilizado como base para resolver determinadas questões, o qual trazia algumas regras e curiosidades em relação ao esporte, além de citar o impacto desse na sociedade atual.

Inicialmente, observou-se que apesar das provas da OBFEP serem dividas em três níveis, como apresentado na Tabela 1, e possuírem um programa distinto de uma série para outra, alguns textos e questões estavam presentes em todos os níveis, pois contemplavam vários conteúdos. Acredita-se que os organizadores esperam que um conteúdo contemplado em uma ou duas questões, exigido no $9^{\circ}$ ano, seja conhecido por estudantes do $1^{\circ}$ ano, inclusive com maior grau de dificuldade. Mas, pode-se observar um número elevado de repetições, por exemplo, no nível C da prova do ano de 2010, na qual havia 10 questões repetidas do nível B, sendo que a prova possui 15 questões.

Importante asseverar que foram encontradas questões que abordam assuntos relacionados ao futebol, mas que não são capazes de fazer relações com a Física no cotidiano. Como exemplo, a primeira questão da parte objetiva, exposta a seguir, solicita que os estudantes transformem o número de praticantes de futebol, citado no texto introdutório, em notação científica:

Qual das alternativas abaixo representa o número de praticantes de futebol no mundo, como indicado no texto?
a) $2,7 \times 10^{2}$
b) $2,7 \times 10^{3}$
c) $2,7 \times 10^{4}$
d) $2,7 \times 10^{6}$
e) $2,7 \times 10^{8}$

Claro que estudantes precisam ter conhecimentos sobre notação científica, porém, esse conteúdo exige apenas conhecimentos matemáticos dos estudantes. Uma questão similar a essa, que trouxesse à tona unidades de medidas atreladas a valores numéricos faria mais sentido e exigiria que o estudante demonstrasse seus conhecimentos a respeito de grandezas físicas.

Em contrapartida, outras questões estavam inteiramente aplicadas ao dia a dia, de tal forma que no momento em que o estudante lesse o problema, iria se lembrar de algo similar que possivelmente já presenciou, e, provavelmente, saberia solucionar a questão, exigindo conhecimentos que não necessitavam terem sido discutidos em sala de aula. Um exemplo disso é apresentado na questão a seguir:

Considerando a massa da bola e seu volume, podemos afirmar que ao ser mergulhada num tanque com água a bola irá: (considere a densidade da água como sendo $1 \mathrm{~g} / \mathrm{cm}^{3}$ e a do ar como $1 \mathrm{~kg} / \mathrm{m}^{3}$ )

a) Como a densidade do ar é menor que a da água a bola irá flutuar.

b) Como a densidade do ar é maior que a da água a bola irá afundar. 
c) A bola irá flutuar totalmente submersa na água.

d) Como a densidade do ar é maior que a da água a bola irá flutuar.

e) Como a densidade do ar é menor que a da água a bola irá afundar.

Apesar de aplicada a situações cotidianas, a questão possui problemas em relação à escrita, uma vez que o verbo que finaliza a questão não está concordando com o início do enunciado das alternativas. Isso mostra uma fragilidade da prova no seu primeiro ano de execução, pois fatos como esse podem dificultar a interpretação dos estudantes em relação ao enunciado das questões.

Ainda neste ano de 2010, no nível A, depois de algumas questões que buscavam uma aproximação com o texto introdutório, foi apresentado um segundo texto que explanou sobre um assunto que foi amplamente comentado nas mídias, relativo à bola utilizada para o evento, popularmente conhecida como "Jabulani", e fez-se deste assunto o tema para as questões seguintes.

Constatou-se que certas questões exigiam apenas interpretações de gráficos, sem requerer maior domínio de determinado conteúdo físico. A maior parte das questões dissertativas resumiu-se a substituição de fórmulas e poucas questões trouxeram aplicações da Física.

Observou-se, em certos casos, que para a resolução de uma questão era necessário alguns valores obtidos na resolução de questões anteriores, fazendo com que uma dependesse da outra, deixando-as fortemente ligadas e exigindo a atenção redobrada do estudante, pois ele poderia não perceber onde encontrar um determinado valor e, além disso, caso o estudante não resolvesse a questão que geraria o dado, provavelmente, não iria resolver a que dele dependesse. Esse tipo de questão privilegia a punição e pode desestimular o estudante a resolver o restante da prova.

No ano de 2011, a prova seguiu, a princípio, o mesmo estilo do ano anterior com texto introdutório sobre um assunto específico, qual seja: o efeito estufa e suas consequências. Porém, apenas as duas primeiras questões abordaram esse assunto, enquanto as outras discorreram sobre grãos, batidas do coração humano, densidade da água e assim por diante. Apareceram outros textos durante o exame, os quais estavam relacionados à energia que os seres humanos utilizam para o funcionamento do corpo, ao terremoto que ocorreu em março de 2011 no Japão e às enchentes no Brasil.

A prova apresentou algumas questões descontextualizas, como um gráfico da posição versus tempo, que representa o movimento de um "corpo qualquer" e não fazia associação a nenhum acontecimento, curiosidade ou aplicação apresentado na prova.

De um nível para o outro os textos eram bem similares, sendo diferenciados por informações extras que foram acrescidas e ajudavam a resolver problemas que envolviam conteúdos relativos ao nível em questão. 
De forma análoga à prova do ano anterior, a prova de 2011 trouxe questões que poderiam ser solucionadas pelos estudantes a partir de suas experiências cotidianas, necessitando basicamente de conhecimento empírico, por exemplo:

O menino no skate decide aumentar sua velocidade ao passar pelo ponto 2. Para isto ele deve:

a) agachar sobre o skate e abrir os braços

b) ficar em pé e com os braços fechados

c) aproximar o peito dos joelhos e fechar os braços

d) ficar pulando no skate

e) sentar no skate com os braços para trás

A prova de 2011 do nível $\mathrm{C}$ trouxe algumas questões interessantes com trechos de livros e de jornais. É apresentado, em uma questão, o manual de uma torneira elétrica disponível no mercado, a partir do qual foram feitas afirmações que o estudante deveria julgar como certas ou erradas.

Ao analisar detalhadamente as questões de 2010 e 2011 e suas resoluções, foram construídos gráficos, representados nas Fig. 1, 2 e 3, que explanam os resultados obtidos em relação aos conteúdos abordados em cada ano para cada nível. Cabe salientar que algumas questões foram classificadas mais de uma vez, por exigirem conhecimentos pertencentes a mais de uma das áreas da Física que compuseram as categorias de análise.

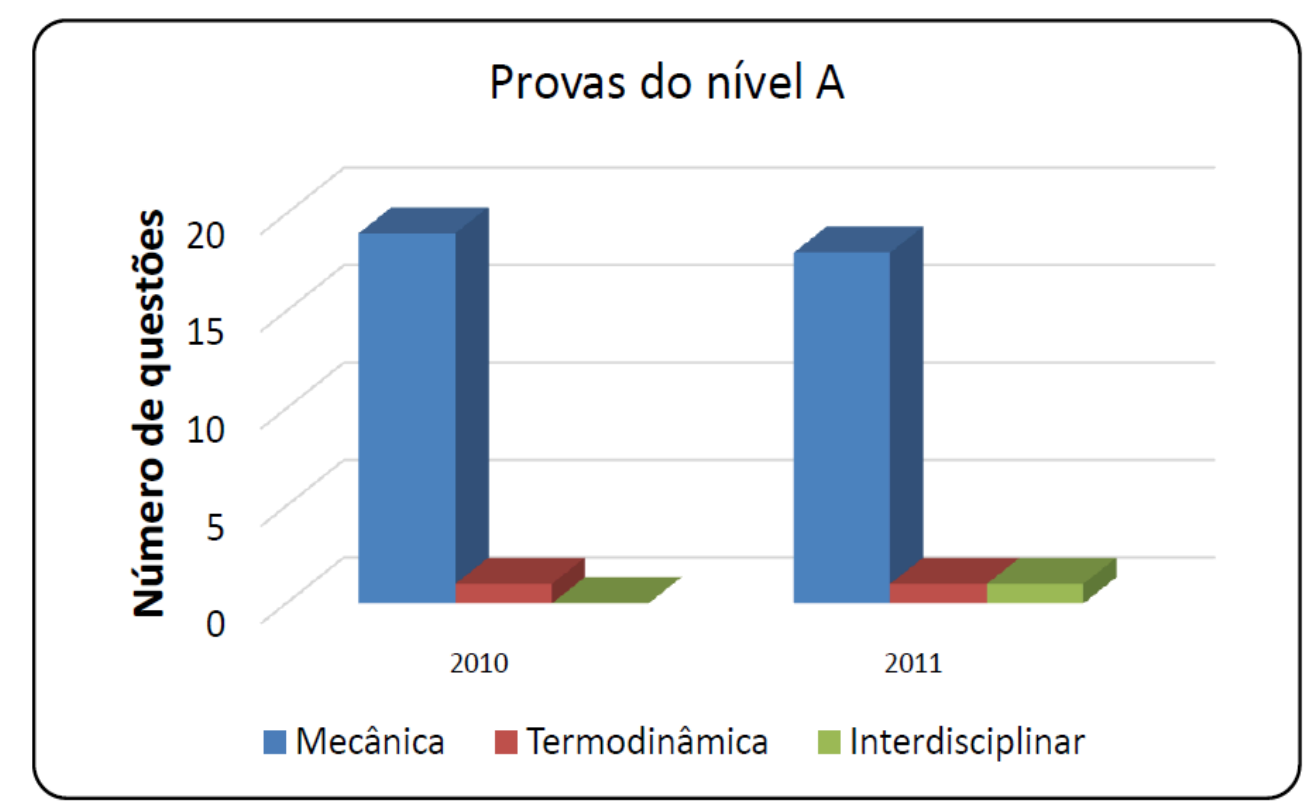

Fig. 1 - Gráfico das provas para o $9^{\circ}$ ano do Ensino Fundamental de 2010 e 2011. 


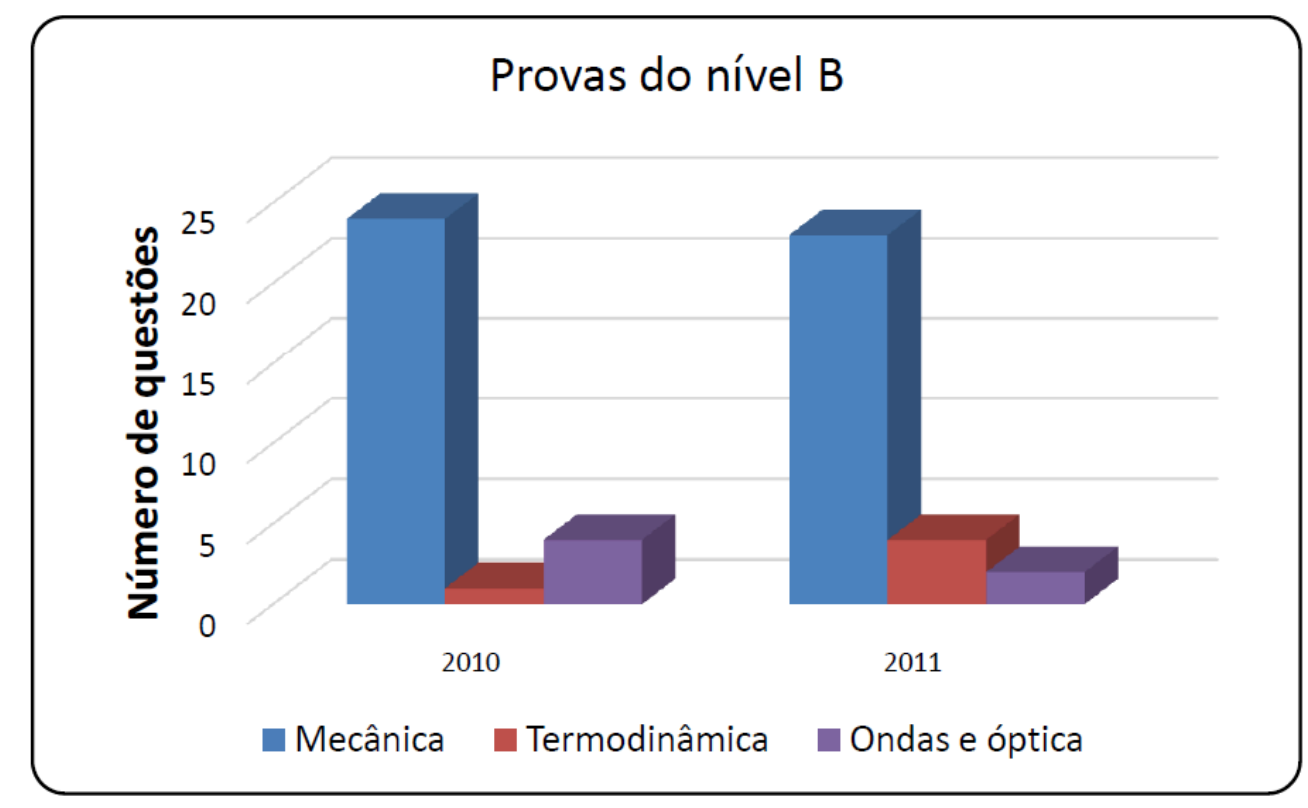

Fig. 2 - Gráfico das provas para os $1^{\circ}$ e $2^{\circ}$ anos do Ensino Médio de 2010 e 2011.

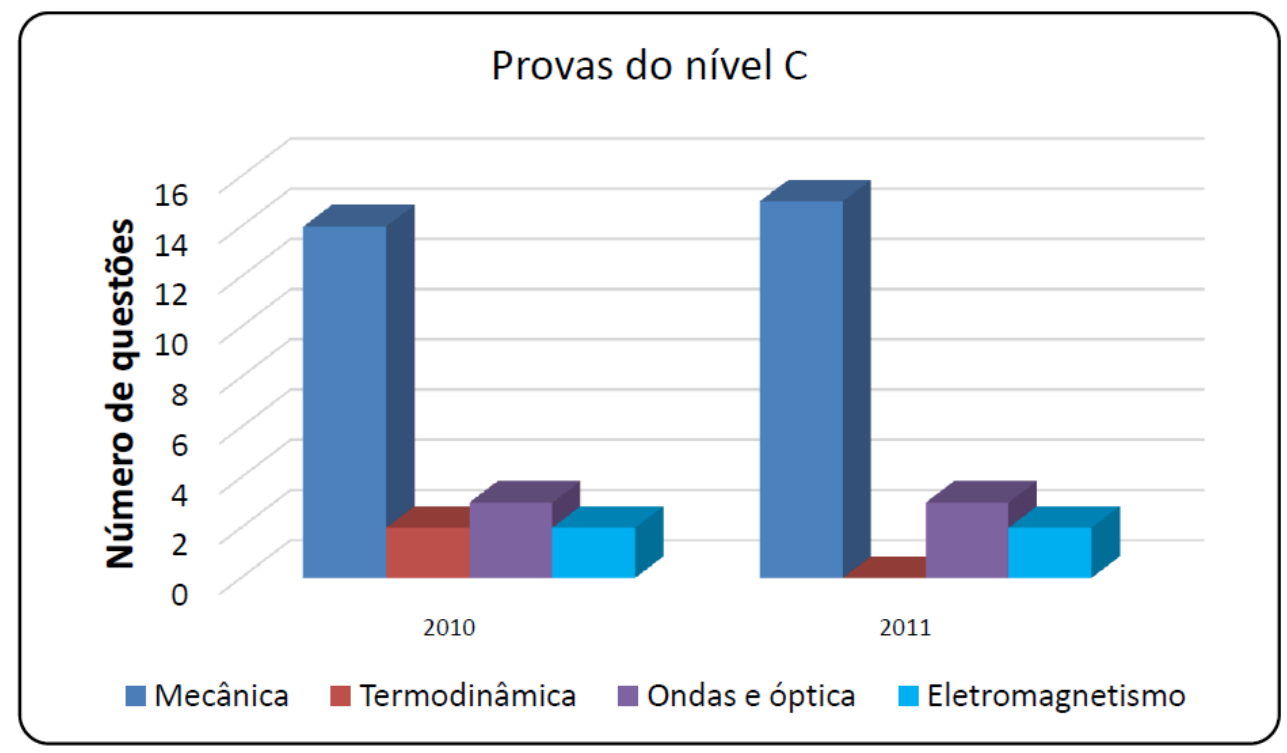

Fig. 3 - Gráfico das provas para o $3^{\circ}$ ano do Ensino Médio de 2010 e 2011.

\section{Segunda Parte: análise das provas dos anos de 2012 a 2015}

No ano de 2012, a OBFEP trouxe o tema "O ano das Olimpíadas em Londres", mas praticamente não havia textos introdutórios ou questões que abordassem o assunto. Dos três níveis, havia uma única questão relacionada a esportes, na qual o estudante deveria calcular o volume de água que desabou sobre o gramado do Maracanã após uma chuva, por meio das dimensões do campo fornecidas no problema. Esta questão pode ser considerada interdisciplinar, já que o estudante deveria utilizar conceitos de geometria para resolvê-la. 
Uma das questões da prova discorreu sobre gincanas escolares e era necessário que os estudantes descobrissem o tamanho de uma árvore sem medi-la. Para resolver esta questão não era necessário nenhum conhecimento físico e, novamente, o estudante necessitava dos conhecimentos em geometria, que é ensinada na disciplina de Matemática. Questões interdisciplinares foram encontradas em todo o exame, atreladas à Matemática e à Geografia.

A maioria das questões, para o nível A e o nível B, se enquadrava dentro dos conteúdos de mecânica e nenhuma delas exigia apenas conhecimentos conceituais, demandando manipulações matemáticas para sua resolução. Pouquíssimas questões contemplavam conteúdos de termodinâmica, de ondas e de óptica. No nível C, o cenário permanece praticamente inalterado, onde a ênfase é dada em mecânica e algumas questões dos demais conteúdos apareceram na prova.

No ano de 2013, cujo tema da prova foi "Ano internacional de cooperação pela água”, constavam apenas duas questões relacionadas à água, sendo que uma pedia para que fosse calculado o volume de água que desabou através de dados pluviométricos em um determinado período e a outra pedia para que o estudante calculasse a altura em que um dado volume de água chegaria no tubo de um cilindro, sendo que essa água estaria em uma esfera. Havia, ainda, questões interdisciplinares que exigiam conhecimentos de Química, como a questão a seguir:

Estima-se que cada gota de água que pinga de uma torneira possui $10^{21}$ moléculas de água. Podemos afirmar que em cada gota existe:
a) $2 \times 10^{21}$ átomos de oxigênio
b) $10^{21}$ átomos de hidrogênio
c) $5 \times 10^{20}$ átomos de oxigênio
d) $2 \times 10^{21}$ átomos de hidrogênio

Essa pequena afinidade entre o tema e as questões ocorre apenas no primeiro nível, uma vez que nos outros níveis não há ligação entre o tema da prova e as questões apresentadas. Neste ano, pela primeira vez, existiram questões totalmente conceituais, porém, o conteúdo predominante também foi mecânica. O nível $\mathrm{C}$ merece destaque, pois estava dividido igualmente entre questões conceituais e de cálculos e, além disso, trouxe a mesma quantidade de questões de mecânica, eletromagnetismo, ondas e óptica, sendo essa considerada a melhor distribuição dos conteúdos dentre todas as provas para o nível C.

No ano de 2014, nada mais justo que o tema abordado fosse "Ano da Copa do Mundo no Brasil”. E, claro, a OBFEP deste ano merece destaque, já que suas questões estavam muito bem contextualizadas e giravam em torno das histórias de um garoto chamado Bisnaga e seu professor Arquimedes. No início da prova havia um trecho apresentando Bisnaga aos estudantes: "Bisnaga era o garoto mais fascinado por futebol de sua escola. Morava em Mossoró (RN) e vivia com um boné do ABC, seu time do coração".

No decorrer de toda prova havia questões que relacionavam a Física ao futebol, por exemplo: 
Bisnaga se surpreendeu com o resultado da experiência de queda livre e tirou o boné sem reclamar. Depois da aula, ele foi jogar futebol com seus colegas. Quando parou um pouco para respirar, viu o professor Arquimedes na arquibancada rabiscando em um caderno. Depois do jogo, foi perguntar ao professor o que estava fazendo e ele lhe mostrou dois desenhos:
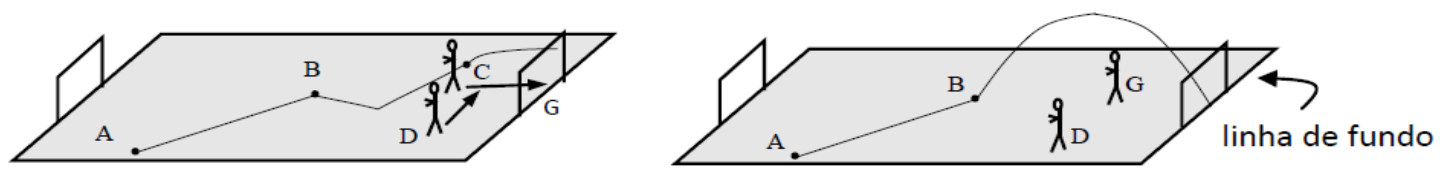

- Bisnaga, eu estava esquematizando uma jogada sua. Enquanto você andava do ponto A ao ponto $\mathrm{B}$, os seus oponentes não mudaram de lugar. Mas, quando se dirigiu de $\mathrm{B}$ para $\mathrm{C}$, de onde chutou a bola para o gol, deu tempo para o defensor D ficar na sua frente e o goleiro $\mathrm{G}$ retornar para a linha de fundo podendo agarrar a bola. Você tem força no pé para dar um chute direto do ponto $\mathrm{B}$, surpreendendo os adversários e encobrindo o goleiro antes que ele retorne à linha de fundo. Usando Física, estava calculando em que direção você deveria chutar.

- Essa tal de Física é muito inteligente. O senhor pode dizer para mim o resultado dos seus cálculos?

- Que tal um desafio? Vou descrever 4 trajetórias que a bola poderia descrever a depender da direção do chute e de sua intensidade. Eu darei três características de cada trajetória: (I) altura máxima; (II) tempo total (subida + descida) e (III) a altura que a bola teria ao cruzar a linha de fundo. Quero que você escolha a trajetória com mais chance para fazer o gol, sabendo que o goleiro tinha $1,8 \mathrm{~m}$ de altura (do pé até o final da cabeça), que ele gastaria $3,8 \mathrm{~s}$ para retornar à linha de fundo e que a altura da trave é $2,2 \mathrm{~m}$.
a) (I) $2,9 \mathrm{~m}$ (II) $4,1 \mathrm{~s}$ (III) $1,9 \mathrm{~m}$,
b) (I) $2,0 \mathrm{~m}$ (II) $2,2 \mathrm{~s}$ (III) $0 \mathrm{~m}$
c) (I) $3,7 \mathrm{~m}$ (II) $1,5 \mathrm{~s}$ (III) $3,5 \mathrm{~m}$
d) (I) 3,2 m (II) 2,9 s (III) $1,7 \mathrm{~m}$

Algumas questões não exigiam do estudante apenas conhecimentos físicos, sendo interdisciplinares e exigindo, também, conhecimentos em Biologia, Matemática e interpretação de texto. As demais questões do nível A estavam divididas entre temas de termodinâmica e mecânica; e a prova estava equilibrada entre problemas conceituais e de cálculo.

O último nível deste ano foi o que menos trouxe questões relacionadas ao tema. No entanto, foi o único em que exigiu do estudante conhecimentos em eletromagnetismo.

No ano de 2015, a OBFEP trouxe como o tema "Ano internacional da luz", porém, não seguiu o mesmo modelo da prova de 2014, na qual a maioria das questões girou em torno das histórias de Bisnaga. Ainda assim, as questões de 2015 estavam bem contextualizadas.

As provas de todos os níveis trouxeram o trecho: "A Assembleia Geral das Nações Unidas decidiu que o ano de 2015 seria considerado o ano internacional da luz", no início de alguma questão. No nível A havia um pequeno texto sobre a descoberta de Fresnel e Einstein e 
era perguntado ao estudante sobre a dualidade onda partícula. Essa questão merece destaque, pois exige dos estudantes do nível A conhecimentos relacionados à física moderna, os quais geralmente não são abordados ou discutidos no último ano do Ensino Fundamental. No nível B o texto falava do comportamento da luz como uma partícula e, apenas nesse ano, foram cobrados conteúdos relacionados à ondas e óptica para os estudantes dos $1^{\circ}$ e $2^{\circ}$ anos do Ensino Médio. No nível C ocorreu uma distribuição bastante igualitária entre os conteúdos das questões.

O tema luz foi bem evidenciado durante o exame, aparecendo em quase metade das questões, sendo que as mesmas iam desde questões em que estudante precisava apenas de geometria para a resolução, mostrando como povos antigos utilizavam a propagação retilínea da luz em benefício próprio, até questões que falavam sobre a dualidade onda partícula.

A prova de 2015 teve uma particularidade, pois em cada um dos níveis havia pelo menos duas questões que citavam astros, estabelecendo relações com conhecimentos de astronomia. Uma questão dessa natureza, constituinte da prova do nível A, pode ser vista a seguir:

A figura abaixo é uma representação das posições do Sol, da Terra e da Lua, e suas dimensões. $\mathrm{O}$ alinhamento desses astros produz um fenômeno raro: o eclipse solar. De acordo com essa figura, os lugares A, B e C, aonde as pessoas poderão ver o eclipse solar total e aonde as pessoas poderão ver o eclipse solar parcial, respectivamente?

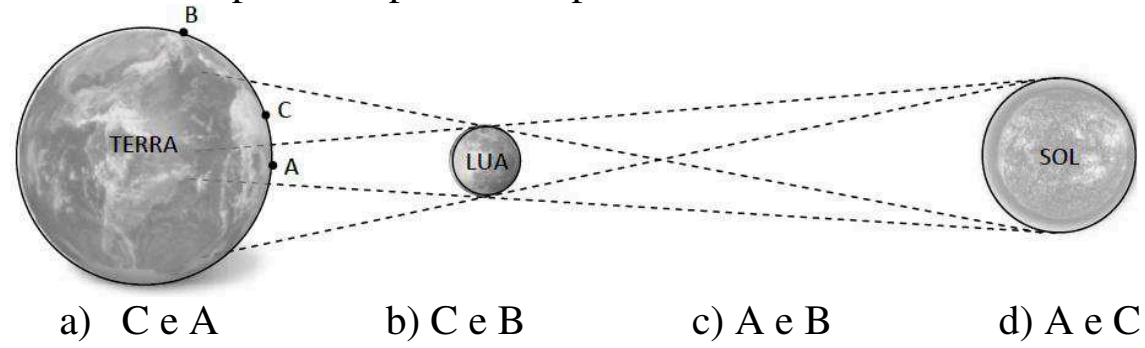

O único nível no qual houve uma divisão quase igualitária entre o número de questões conceituais e que exigiam cálculos foi o $\mathrm{A}$, pois nas provas de níveis $\mathrm{B}$ e $\mathrm{C}$ a maior parte das questões exigia dos estudantes cálculos matemáticos. A única prova que exigiu conhecimentos em eletromagnetismo foi a de nível $\mathrm{C}$.

Pode-se destacar a prova de nível A de 2015, pois foi o único nível, dentre todos os níveis em todos os anos analisados, que teve mais questões interdisciplinares do que de mecânica, além de exigir dos estudantes conhecimento em física moderna. As demais provas exigiram na maioria das questões conhecimentos de mecânica.

Nas figuras seguintes são apresentados os gráficos referentes à distribuição dos conteúdos das provas da OBFEP nos anos de 2012 a 2015. 


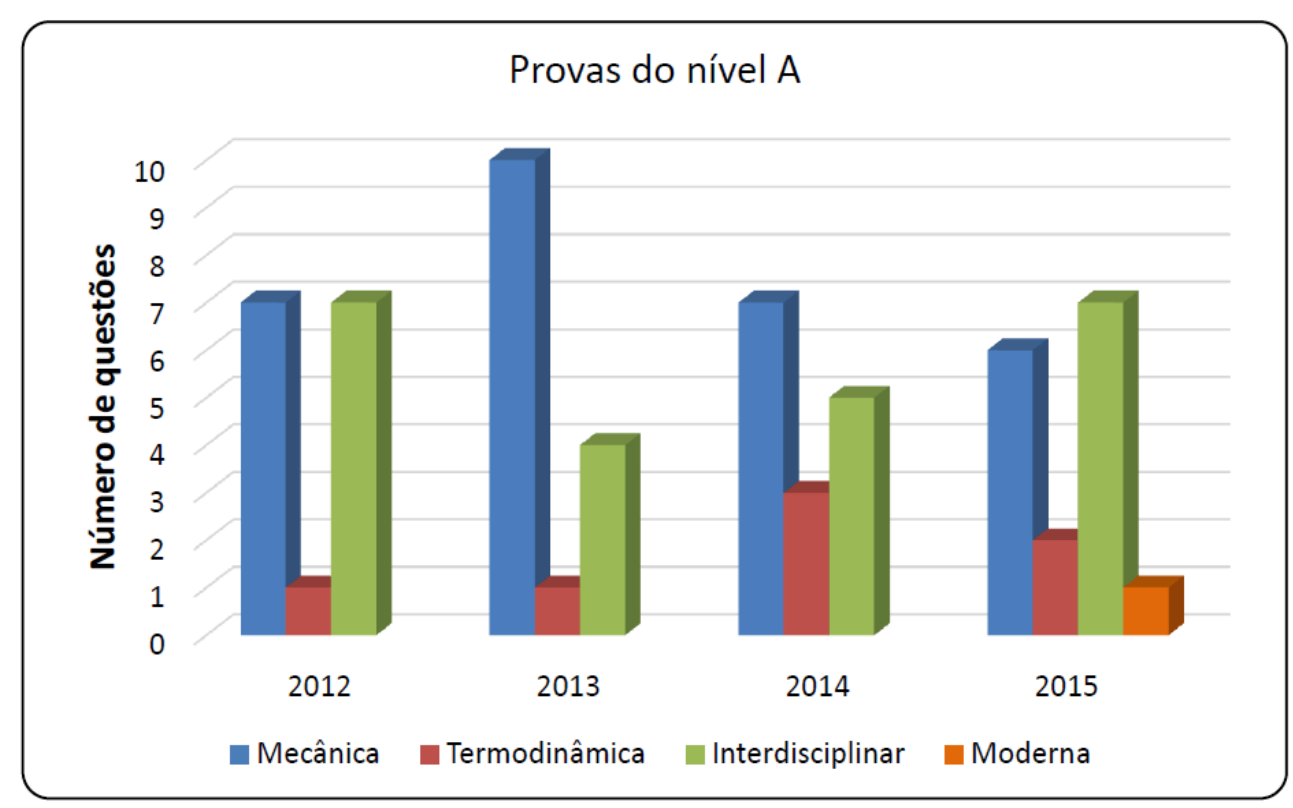

Fig. 4 - Gráfico das provas para o $9^{\circ}$ ano do Ensino Fundamental de 2012 a 2015.

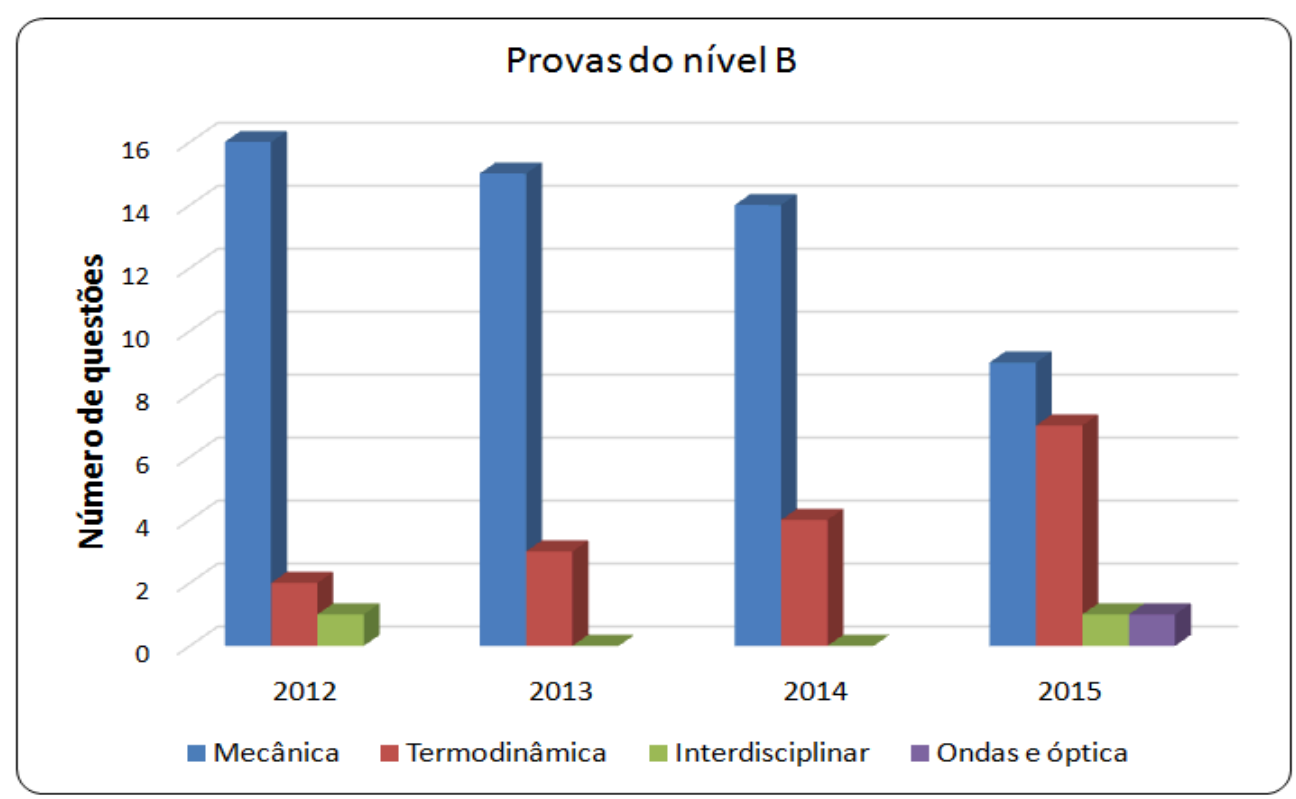

Fig. 5 - Gráfico das provas para os $1^{\circ}$ e $2^{\circ}$ anos do Ensino Médio de 2012 a 2015. 


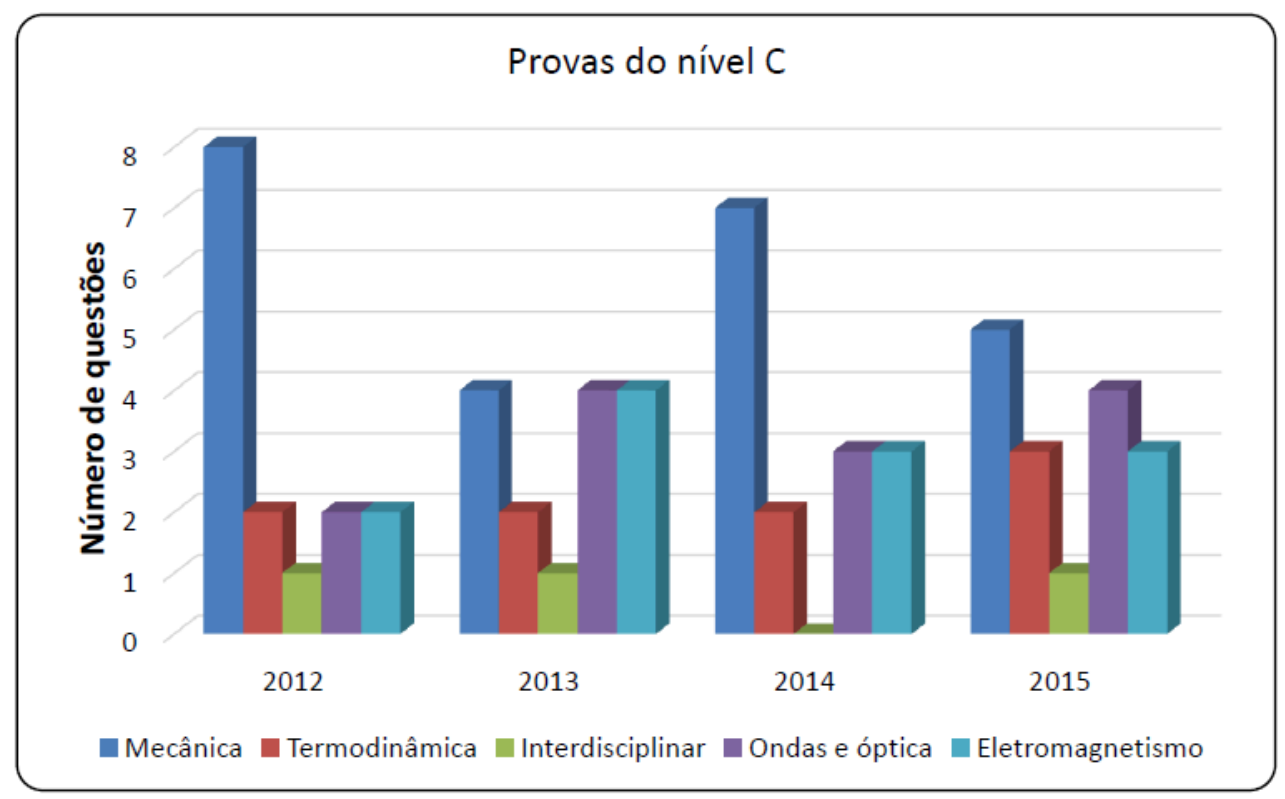

Fig. 6 - Gráfico das provas para o $3^{\circ}$ ano do Ensino Médio de 2012 a 2015.

Em relação à divisão geral dos conteúdos exigidos durante todas as provas da OBFEP observou-se a predominância da mecânica. A termodinâmica foi o segundo conteúdo mais cobrado, seguido por questões interdisciplinares, ondas e óptica, eletromagnetismo e física moderna, que esteve presente em apenas uma das questões de todas as provas analisadas, como pode ser visualizado na Fig. 7.

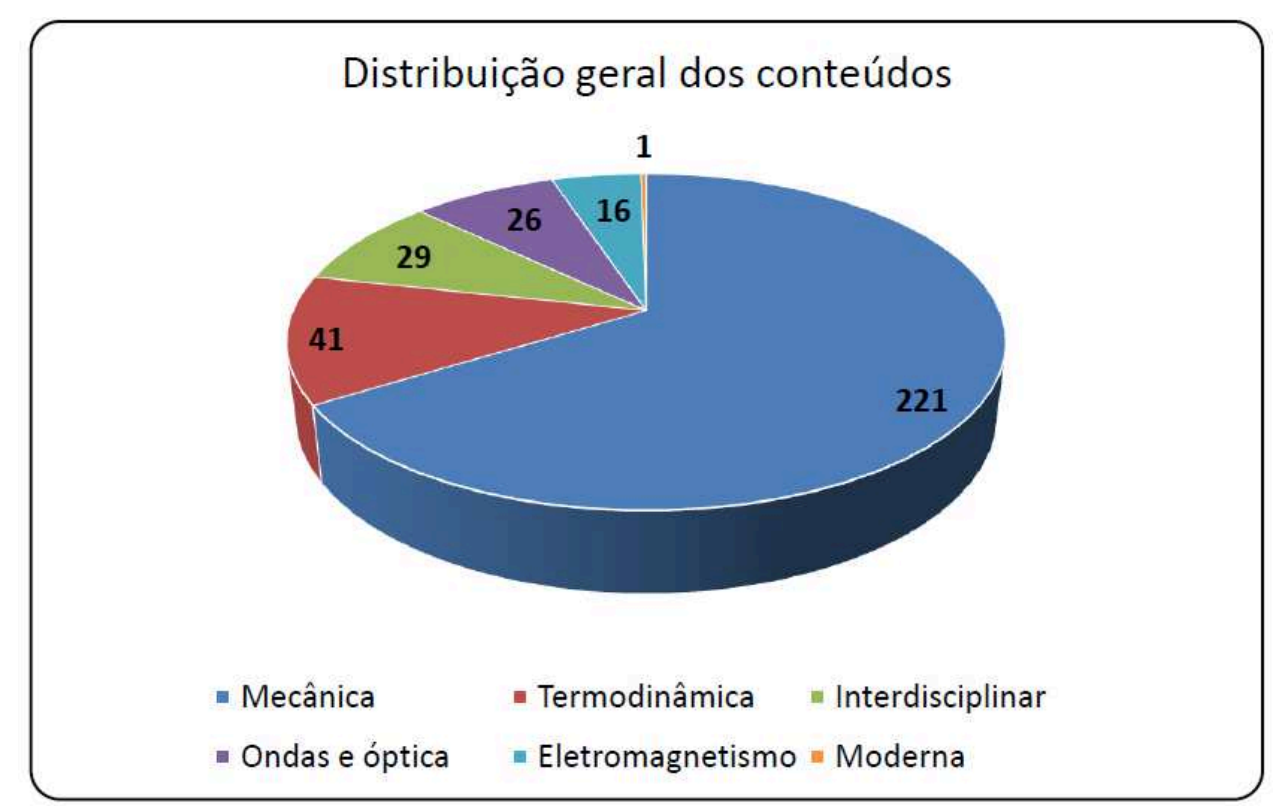

Fig. 7 - Gráfico quantitativo de distribuição dos conteúdos das questões das provas da OBFEP de 2010 a 2015. 


\section{Considerações finais}

A partir das análises das provas, foi possível verificar que, em quase todos os anos, a OBFEP trouxe um tema estruturador atual para cada edição do exame e que em suas duas últimas edições o tema foi mais explorado que nos anos anteriores, a tal ponto de fazer um dos exames, o de 2014, demasiadamente baseado em um determinado assunto. Verificou-se que em alguns anos o tema da OBFEP era similar ao tema da OBF, como, em 2012, cuja temática para as duas olimpíadas estava relacionada aos jogos olímpicos de Londres, e, em 2015, cujas temáticas estavam voltadas para o ano internacional da luz.

De fato, em todas as edições da OBFEP o conteúdo mais exigido foi mecânica, ou seja, independentemente do nível em que o estudante esteja é crucial o domínio de tal conteúdo para conseguir um bom resultado no exame. Em todas as provas, com exceção do nível C de 2011, é cobrada ao menos uma questão de termodinâmica. Os conteúdos de ondas e óptica aparecem em metade das provas do nível B e em todas do nível C. Da mesma forma, os de eletromagnetismo aparecem em todas as provas do nível C. Isso é bastante compreensível uma vez que tais conteúdos são discutidos em diferentes momentos formativos dos estudantes do Ensino Médio e, além disso, no programa oficial para as provas, os conteúdos de eletricidade e magnetismo aparecem apenas na relação dos conteúdos destinados ao nível C. Apenas no ano de 2015 foi contemplado o conteúdo relacionado à física moderna e esse estava presente no nível $\mathrm{A}$, o que contraria o argumento utilizado anteriormente uma vez que no programa oficial das provas não constam exigências de conhecimentos sobre física moderna para o nível A. Vale salientar que o tema da prova de 2015 foi o ano internacional da luz o que pode ter viabilizado a inclusão de tal questão no nível A.

A análise do programa oficial das provas mostrou que os tópicos a serem cobrados nas provas são apresentados nos mesmos moldes de exames tradicionais, como vestibulares e concursos, sem uma maior relação com os temas estruturadores sugeridos nos $\mathrm{PCN}+$ para o ensino de Física.

Com o passar dos anos houve maior preocupação em relação à interdisciplinaridade $\mathrm{e}$ contextualização, pois foi crescente o número de questões dessa natureza. As provas do ano de 2014 merecem destaque, uma vez que estavam bem contextualizadas e giraram em torno de uma única história, por consequência, exploraram mais interpretação de texto e exigiram mais atenção dos estudantes.

Sem dúvida, as provas da OBFEP se mostram mais adequada para à realidade dos estudantes das escolas públicas quando comparadas às provas da OBF. As questões possuem níveis de dificuldade diferenciados em relação às questões da OBF. Ademais, a OBFEP possui apenas duas fases, fato esse que viabiliza sua aplicação sem incorrer em prejuízos quanto à carga horária dos estudantes, uma vez que na grande maioria das escolas públicas são lecionadas apenas duas aulas semanais de Física. Porém, um fato a ser observado e que pode estar um pouco longe da realidade vivenciada pelos estudantes que realizam a OBFEP, está relacionado às questões práticas que começaram a surgir em 2012, na segunda fase das provas, uma vez que 
a maioria das escolas públicas não possui laboratórios didáticos nos quais os estudantes possam desenvolver habilidades para tal.

Os resultados obtidos auxiliaram a compreender mais sobre o perfil das provas da OBFEP e sobre os conteúdos que são mais exigidos para a realização do exame. Todavia, não é possível prever como será a prova de 2016, a qual terá como tema "Os Jogos Olímpicos do Rio de Janeiro", mas se espera que siga o modelo das provas de 2014 e 2015, trazendo questões contextualizadas, com aplicações da Física relacionadas ao dia a dia, demonstrando aos estudantes que a Física está presente em, praticamente, todos os lugares, bem como ela pode ser utilizada para simplificar e resolver problemas cotidianos.

O conhecimento das provas da OBFEP pode auxiliar a encontrar lacunas presentes na formação dos estudantes, contribuindo para a criação do novo Ensino Médio. Professores podem analisar o resultado de seus estudantes no exame e identificar quais conteúdos necessitam de revisão ou de uma atenção especial.

Os resultados obtidos e evidenciados na Fig. 7 corroboram com os obtidos por Erthal e colaboradores (2015) os quais fazem uma análise das questões sobre as provas da OBF e verificam que a predominância das questões, em todas as edições das provas, é relacionada aos conteúdos de mecânica e que raramente são exigidos conhecimentos sobre física moderna.

Um resultado a ser destacado é o número expressivo de questões interdisciplinares, em especial nas provas de nível A dos anos de 2012 e 2014, o que demonstra uma adequação das questões às propostas educacionais atuais, que privelegiam conhecimentos interrelacionados em diferentes áreas do conhecimento.

Deseja-se que este trabalho possa incentivar a reflexão dos professores do Ensino Médio sobre o potencial que as provas da OBFEP possuem no processo de ensino aprendizagem, além de estimular a instauração de uma cultura de participação e de utilização das questões da OBFEP no contexto escolar.

\section{Referências}

ERTHAL, J. P. C. et al. Análise e caracterização das questões das provas da Olimpíada Brasileira de Física. Caderno Brasileiro de Ensino de Física, Florianópolis, v. 32, n. 1, p.142-156, 2015.

GASPAR, A. Física. 1 ed. São Paulo: Ática, 2005. v. único.

NAKAMURA, O.; MARTINS, M. G. R.; GUTMANN, F. W. Olímpiada Brasileira de Física das Escolas Públicas: problemas e resoluções 2010-2011. 1 ed. São Paulo: Sociedade Brasileira de Física, 2012. 217 p. v.1.

OBFEP: Credenciadas na OBFEP 2015. Disponível em: <http://www.sbfisica.org.br/ obfep/obfep-2015/credenciadas-na-obfep-2015-2/>. Acesso em: 13 mar. 2016. 
OBFEP: Regulamento 2016. Disponível em: <http://www.sbfisica.org.br/ obfep/regulamento/>. Acesso em: 16 abr. 2016.

REZENDE, F.; OSTERMANN, F. Olimpíadas de ciências: uma prática em questão. Ciência \& Educação, v. 18, n. 1, p. 245-256, 2012.

VIANNA, J. D. M. et al. Olimpíadas de Física. Revista Física na Escola, São Paulo, v. 1, n. 1, 2000. 